\title{
The Spanish Survey of Living Conditions (ES-SILC). Characteristics and methodological development
}

\author{
José María Méndez Martín \\ National Statistical Institute of Spain (INE)
}

\begin{abstract}
The Encuesta de Condiciones de Vida (Spanish SILC Survey) is an annual survey integrated in the European Statistics on Income and Living Conditions (EU-SILC). The primary aim of this survey is the regular production of statistics on household income and living conditions, collecting key variables like the total household income and the income components. Initially income information was obtained using exclusively the questionnaires. Nevertheless, access to administrative records offers a good opportunity to improve the quality of income data and allows the use of a more efficient collection method. In 2013 a new methodology was adopted in ES-SILC for the production of the income variables based on the use of administrative files (data from the Spanish Tax Agency and the Social Security system), in combination with the information available in the questionnaires. This paper offers a comparative overview of both methodologies assessing the impact on the main indicators. Also the future scheme of this statistical operation in 2021 is introduced. The new design of the contents will be based on a series of rotating modules that will cover different dimensions of the living conditions of the household.
\end{abstract}

Keywords: Survey of Living Conditions, household income, administrative data

MSC: 62P20, 62P25, 91B82

\section{Introduction}

This paper is elaborated in the frame of a peer review process that is part of the European Statistical System (EES) strategy to implement the Code of Practice (CoP). In the last peer review to INE Spain there is a recommendation (Recomm.10) to carry out the assessment of key statistical operations by external experts. To fulfil this recommendation a session has been organized in the context of the XXXVIII Spanish Conference on Statistics and Operational Research, and the XII Conference on Public Statistics to present the methodology to the Spanish Survey of Living Conditions (ES-SILC), having two discussants from the Complutense University of Madrid and the Office of the High Commissioner against Child Poverty.

The structure of the paper is as follows: It first presents a description of the characteristics and objectives of the survey and the treatment of one of the key variables of the survey, the household 
income; the following sections describe the evolution of the ES-SILC methodology, from the initial version entirely based on sampling surveys, to the current methodology, which combines surveys with administrative sources; next, some of the main indicators obtained from these surveys are commented on, such as the poverty line or the AROPE indicator, as well as some effects that changes in the methodology have had on these indicators. In a final section future novelties planned for this survey are described, an analysis that the author takes advantage of precisely to evaluate some of the suggestions made by the discussants in the round table.

\section{Background}

The Spanish Survey of Living Conditions (ES-SILC), integrated in the European Statistics on Income and Living Conditions (EU-SILC), belongs to the set of harmonized statistical operations for the countries of the European Union. The fundamental objective pursued with EU-SILC is to have a reference source on comparative statistics of income distribution and social exclusion in Europe.

EU-SILC is not the first harmonized statistical operation of income and living conditions that is carried out in Europe. Between 1994 and 2001, the European Community Household Panel (ECHP) survey met these needs. ECHP was configured as a pure panel in which the households of a sample selected in 1994 were followed for 8 years, without performing any sample rotation during those years. However, since it was necessary to update its content according to the new demands, it was decided to replace the ECHP survey with a new instrument.

The Commission developed a community action program to promote cooperation between Member States in the fight against social exclusion, which was presented in 2000 to the European Parliament and the Council, to promote the collection and dissemination of comparable statistics in the Member States and at the community level.

In this framework it was decided to replace ECHP from 2002, by another survey that adapted its contents to the new information needs coming from public and private sectors and to the aim of improving the quality of the information, in particular regarding the timeliness of the data. After several studies and preparatory meetings, a pilot test was conducted in 2002, and in 2004 the final survey was initiated in most countries, including Spain (INE, 2005).

\section{General description}

This statistical operation is legally supported by a set of Regulations published in the Official Journal of the European Union, which determine the commitments acquired by the Member States and Eurostat in relation to the survey.

Regulation (EC) 1177/2003 of the European Parliament and of the Council concerning Community statistics on income and living conditions is the framework regulation that provides legal support to the EU-SILC. This Regulation specifies the objectives of the new statistical instrument, the areas included, the time reference, the calendar of data availability and some quality requirements such as the effective sample size. It clearly defines the responsibilities of the Member States and Eurostat, resulting in the quality of the new instrument.

While the Regulation of the Parliament and of the Council identifies the general legal basis of the new operation, the Commission Regulations detail the target variables that the statistical source includes, the fieldwork aspects, the sampling, etc. Concerning the definitions the survey follows the recommendations for income data of the International Expert Group on Household Income Statistics (United Nations, 2011). 
Although the priority in this survey is the production of cross-sectional information (data produced year by year) with a high degree of quality in terms of its timeliness and comparability, the survey also collects longitudinal information referring to the same sample at different years over time (in the Spanish case, the follow-up is carried out over four years). The inclusion of a longitudinal component makes the survey more complex since the households in the sample have to be followed in the different years.

ES-SILC has a final sample size of about 13,000 households. The mode of data collection is CAPI and the interviews are conducted normally between April and July (although exceptionally there have been years in which it has been collected after the summer), publishing the results around May of the following year.

\subsection{Main areas of study}

The areas of study included in ES-SILC can be classified according to the periodicity of the data collection. The primary areas are those whose collection is carried out annually, while the secondary areas contain the variables that are included in the modules that can change every year. Currently, the part corresponding to the primary areas represents the largest part of the survey, while the part dedicated to the annual module is very small. The primary areas covered by ES-SILC are the following, depending on the type of unit of observation:

- Household

- Total household income and household income components.

- Arrears on payments.

- Non-monetary indicators of deprivation (difficulties in making ends meet, level of indebtedness, enforced lack of basic needs, etc.).

- Physical and social environment.

- Dwelling type, tenure status, housing conditions.

- Housing cost.

- Persons (adults)

- Demographic data.

- Total personal income and personal income components.

- Education.

- Basic labour information on current activity, including information on last main job for previously active people.

- Calendar of activities during the income reference period.

- Health and access to health care.

- Persons (children)

- Demographic data.

- Childcare.

The areas of study were reduced compared to those considered in ECHP, which results in a higher quality of data.

Since the 2005 survey a module is introduced every year addressing a specific topic of interest. The modules that have been included during these years are:

- 2005: intergenerational transmission of poverty.

- 2006: social participation. 
- 2007: housing conditions.

- 2008: over-indebtedness and financial exclusion.

- 2009: material deprivation.

- 2010: intra-household sharing of resources.

- 2011: intergenerational transmission of disadvantages.

- 2012: housing conditions.

- 2013: well-being.

- 2014: material deprivation.

- 2015: social participation.

- 2016: access to services.

- 2017: health.

- 2018: well-being and housing difficulties.

- 2019: intergenerational transmission of disadvantages.

- 2020: over-indebtedness, consumption and wealth.

\subsection{The integrated design}

The integrated design combines in a single operation the cross-sectional component (year-to-year results) and the longitudinal component (follow-up of households over a period of time). It was the design recommended by Eurostat in those cases in which it was decided to develop a new survey, being the model adopted by Spain.

The integrated design of ES-SILC consists of a rotating panel survey. Therefore, being a panel, the same units are investigated over the years, but unlike ECHP, which was a pure panel and the panel units were followed for eight years, in ES-SILC the panel units are followed only for four years.

The sample consists of four panel subsamples (four rotating groups), so that each year one of them is replaced by a new subsample. Each of the subsamples remains in the survey for four years, being afterwards replaced by another subsample.

An important advantage of this model is that most of the sample used to obtain the longitudinal component is derived from the cross-sectional sample: the cross-sectional and longitudinal statistics are obtained from the same set of units avoiding duplication in the response burden of the survey.

\subsection{Quality in ES-SILC}

The ES-SILC is integrated in the Spanish Statistical System, and in the European Statistical System, within which there are various quality control mechanisms.

\subsubsection{Quality management at the Spanish National Statistical Institute}

ES-SILC is carried out by the Spanish National Statistical Institute (NSI), and belongs to the set of statistics included in the National Statistical Plan. The tasks of the Spanish NSI in relation to statistical production are "the production, within the indicated deadlines, of adequate, reliable and consistent statistics, as well as making available to users the statistical information necessary to facilitate decision-making".

The Spanish NSI, on its website, dedicates a special section to the Quality and Code of Good Practices, showing the importance given to this aspect in official statistics. In this section, the organization established for quality management in the Spanish NSI is presented, based on three basic elements: 
- An administrative structure. The Spanish NSI has a Quality Unit with this objective, as well as a Quality Committee, where the lines to be followed are discussed.

- A quality evaluation and monitoring system. The instruments are the preparation of quality reports and indicators, user surveys and external evaluation (Peer Review).

- Other quality components. Among others, there are the dissemination, confidentiality and review policies, and the quality assessment and monitoring policies of the Spanish Public Administration.

The implementation of the Code of Practice in the National Statistical Plan from the European Statistical System (ESS) has a special role in quality management.

\subsubsection{The quality of statistics in the ESS}

The quality at EU level is based on the adoption by the Statistical Program Committee (SPC, current ESSC) of the European Statistics Code of Practice, in 2005. In its current version (2017) the code sets out 16 key principles, which are reviewed periodically. Its objective is to establish a standard for the development, production and dissemination of European statistics, as well as to ensure the quality and credibility of the data.

It is structured in three sections covering the institutional environment, statistical processes and statistical outputs.

All statistics produced within the European Statistical System are subject to the Code of Practice. But in the case of ES-SILC, in addition, its production is legally supported by various regulations that specify all methodological and procedural aspects.

The framework Regulation of this operation is the above-mentioned Regulation (EC) $1177 / 2003$ of the European Parliament and of the Council, which establishes the legal basis of the production of the EU-SILC. On the other hand, there are several Commission Regulations that address each and every one of the harmonized methodological aspects.

Among these legislation there is also a specific regulation dedicated to the quality of the EU-SILC. Commission Regulation (EC) 28/2004 describes in detail the intermediate and final quality reports of the EU-SILC that all Member States must send to Eurostat. Eurostat subsequently generates a comparative quality report where you can see the weaknesses and strengths of the survey. In addition Eurostat carries out a review of the survey data before the results are published.

\section{Income in ES-SILC}

One of the main objectives of the survey is the analysis of household income received during the reference period. The income reference period adopted in ES-SILC is annual from January to December of the calendar year preceding the interview.

This statistical operation collects personal income of the household members and also household income components of those sources that are difficult to individualize. Thus, this survey collects personal income in individual questionnaires (persons aged 16 years or older). On the other hand, in the household questionnaire other income components are collected (property income, housing assistance, etc.) that are more typical of the household as a whole. All this aggregate information allows to build the total household income.

The total disposable household income is calculated as follows (net of tax on income at source and social contributions):

+ Monetary employee income 
+ Non-monetary employee income (company car)

+/- Profits / losses from self-employment

+ Capital income

+ Property income

+ Social benefits (unemployment, retirement, etc. )

+ Pension from individual private plans

+ Regular inter-household cash transfers received

+ Income received by children under 16

- Regular inter-household cash transfers paid

- Repayments/receipts for tax adjustments

- Regular taxes on wealth

\subsection{Gross and net income}

In EU-SILC, the income target variables include the collection of gross amounts at the level of individual and income component. This allows a better comparability between Member States to analyze income components, because it will not depend on the tax system or the social security contributions of the country. It should not be forgotten that the objective of EU-SILC is not only to obtain information at country level, but also to obtain comparable data among Member States of the European Union, which requires a standardized use of definitions and methodologies.

However, at the aggregate level, the key variable is the total disposable household income, in particular for studies of income distribution and poverty.

\subsection{Monetary and non-monetary income}

ES-SILC collects some non-monetary income components, although they are not always included in the definition of total disposable household income:

- Company car for employees

- Other non-monetary employee income, such as luncheon vouchers

- Employer's social insurance contributions

- Imputed rent

- Value of goods produced for own consumption (value of food and beverages produced and consumed within the same household)

Currently, in the definition of the total disposable household income, only the company car for employees is included.

\section{Methodology based on Sampling Survey (base 2004)}

At the beginning of ES-SILC from 2004, the data collection methodology was carried out through sampling survey procedures and the use of questionnaires. Since 2013 the methodology was changed complementing the data sources with the use of administrative files.

Since 2004 the method of data collection has been mainly the personal interview (CAPI) with all the household members of the dwellings surveyed. The interviewer contacts the household and requests the information necessary to complete the questionnaires, making all the necessary interviews to collect the required information. In this way, both the information related to income and the rest of the variables related to the living conditions of the household are collected. The questionnaire 
collects income data during the interview through some alternative questions that try to facilitate the response. Taking into account that the reference period is annual, it is usually requested in the question for an amount and for the number of times received. The possibility of providing annualized amounts is also usually offered.

One of the greatest difficulties in collecting income data from the respondents is the lack of knowledge of the gross amounts, or of the taxation of income at source. This has made necessary the use of net-gross models to impute the gross amounts.

In the 2013 survey, a new base was started with the use of administrative files. However, the collection of all the income information in the questionnaires was continued until 2014, simplifying the questionnaire from 2015 due to the suppression of many questions related to income amounts.

\section{Methodology based on the use of administrative files (base 2013)}

In 2013 a new methodology was adopted in ES-SILC in the production of data on household income based primarily on the use of administrative files, combined with information available on the questionnaires. Access to administrative records has meant an improvement in data quality and efficiency in the method of data collection.

Data related to household income are obtained using a mixed methodology combining the information provided by the respondent to the surveys with the administrative records of the Spanish Tax Administration, Social Security, and the Tax Administration of Navarra, Bizkaia and Gipuzkoa.

Due to the change in methodology, there is a break in the time series that makes the income data not comparable with the data published in previous years. For this reason, retrospective data have been produced since 2008 using the new methodology based on administrative files, which are comparable with 2013 data.

Within the European Union, the increasing use of administrative data in statistical production is an essential element in the process of modernization of social statistics. Many countries use administrative files in this survey for the production of income variables. Apart from the Nordic countries, Netherlands, France, Austria or Slovenia make very important use of administrative files. In other cases, partial use is made of them covering mainly the social benefits variables (Eurostat, 2013).

\subsection{Method of data collection}

The methodological change involves mainly collecting the income variables using the administrative files. From the Tax Identification Number (NIF, personal identification) of the sample persons, data from the Tax and Social Security Sources are collected and, together with the data collected in the questionnaires, the construction of the income variables is carried out.

In the production of income variables by components from administrative files, in a first approximation the methodology would be to identify the corresponding field or fields of the corresponding administrative forms, and do the appropriate processes to obtain the required target variables.

This procedure is valid in some cases, but in other income components we observe that an exclusive use of administrative files in their construction is difficult. This is due to the problems that arise in relation to the geographical coverage (no tax data are available in Alava), coverage of income recipients (problems in certain groups such as domestic employees, the informal economy, etc.) or problems with the precise identification of the income component in the administrative file. In these cases, complementary information is collected through the personal interview to construct the income target variables. 
Finally, combining data from the survey and the administrative files, the variables related to income are constructed. In few cases in which the amount cannot be captured from any of these two sources, mathematical imputation is necessary. The merge of the sample persons with the administrative data is done through the Tax Identification Number (NIF). The capture of the NIF in ES-SILC was first introduced in the 2009 survey, covering around $98 \%$ of adults.

\subsection{Construction of the target income variables}

The methodology of using administrative files is not direct. In an ideal/naive situation it would consist in exchanging amounts (see Figure 1). The amounts that have been collected through the questionnaire, now are collected by taking certain fields of the corresponding forms of the administrative files:

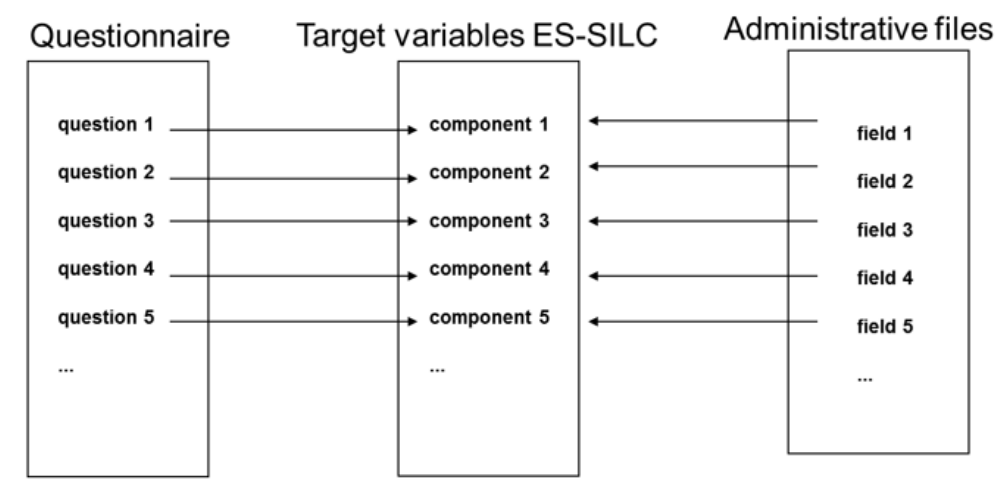

Figure 1: Links among target variables and data provided by sources: Ideal situation.

However the real situation is more complex. From the perspective of the questionnaire, without taking into account the non-sampling errors of any household survey, there can be measurement and classification errors like, for example, having an amount collected in a question corresponding to more than one target income variables of ES-SILC (for example, the question that collects employee income may mistakenly include sickness benefits).

From the perspective of the administrative file the situation is even more complicated. The correspondence between fields of administrative forms and amounts of the target variables is sometimes not direct as it is shown in Figure 2.

This situation makes it necessary to control the risk of duplicity. An amount to be loaded from the questionnaire in a certain target variable may already be included in some cases in other variable in the load from the administrative file.

For this reason, in the construction of the target income variables we will consider two types of variables:

- Individual variables of direct construction. The variable is loaded from the questionnaire or the administrative file. There are no risks of duplicity in the sense of having the amount already collected in another variable. In this situation we have, for example, inter-household transfers (obtained from the questionnaire) or capital income (obtained from the administrative file).

- Group of variables in which the procedure must be in block to avoid risks of duplication. For example, employee income, income from self-employment and some social benefits (sickness, maternity) do not have a clear allocation of amounts. From the perspective of the questionnaire, amounts of one component can be filled in another (for example, income from self-employment 


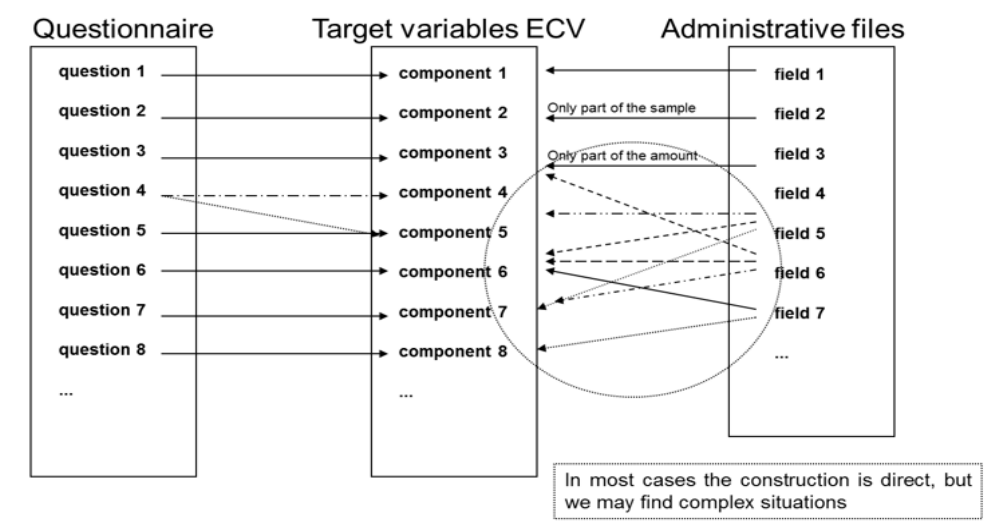

Figure 2: Links among target variables and data provided by sources: Real situation.

can be considered by the respondent as employee income, and vice versa). From the perspective of the administrative file, there may also be problems in separating, for example, sickness benefits from employee income. In these cases, we will take all the amounts either from the administrative file or from the questionnaire. In the case of taking the data from the questionnaire, the information available in the administrative file can be used to improve the construction of the target variables.

The loading strategy is summarized in Figure 3, which shows the origin of the different income components (comp 1, comp 2, etc.) for the different records or sample units:

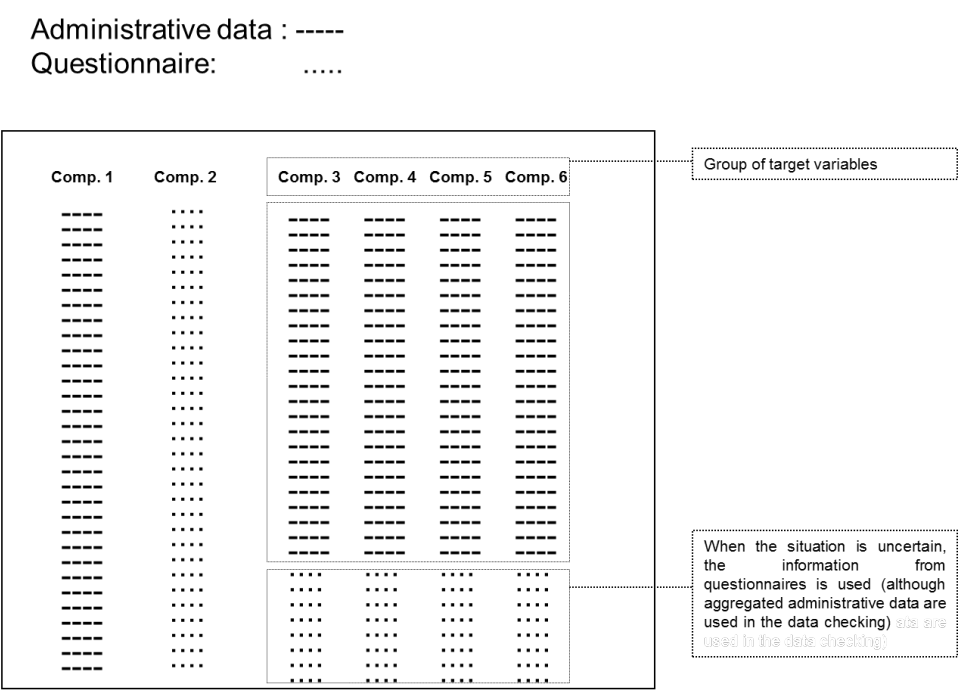

Figure 3: Origin of the different income components (comp 1, comp 2, etc.) for the different records or sample units. 


\subsection{Administrative sources}

\subsubsection{Register of Public Social Benefits. Social Security Sources}

The Social Security is the managing administration of numerous social benefits having lots of information that covers the entire national territory. However, there are a number of social benefits, mainly non-contributory pensions, that are managed from the Autonomous Communities and that are outside the scope of Social Security management.

However, the Social Security is responsible with the management and operation of the Register of Public Social Benefits. The creation of this registry allows coordinated knowledge and transfer of data between public entities, in order to facilitate the allocation of benefits, as well as avoiding fraud.

Therefore, the Social Security is the owner of this register, with data regarding the benefits paid by management entities of the Social Security System as well as bodies outside this system.

\subsubsection{Forms 190 and 100. Tax Sources}

Currently there are data are available from the Tax Agency (AEAT), and the tax administrations of Navarra, Bizkaia and Gipuzkoa.

Initially, the information contained in the Income Tax Returns is rich enough to know the different components of income in the households in the sample. However there are some difficulties. In particular, the group of those not obliged to fill the tax returns is quite important and, on the other hand, the possibility of family joint declaration makes difficult the individualization of income required by the ES-SILC.

For this reason it is essential the access to other information available in the Tax Sources. We must keep in mind that the tax returns are in fact an annual adjustment of the taxes that have already been paid during the year in a system of withholdings and taxes paid at source.

Besides the Income Tax Returns, the Tax Administration have extensive information. In particular, there is a form with the annual summary of withholdings and taxes at source (Form 190 of the Tax Agency) that contains individual information on different income components, including income recipients who are not obliged to fill the tax return. Detailed information on it can be found in the regulations regarding this form.

This register contains useful information for constructing the employee income variable and some social benefits (there are some fields that identify the income component or subcomponent).

On the other hand, Form 100 (Tax Agency) contains the Income Tax Returns. Although Form 190 is initially used as the main source of information, in the case of income from self-employment, capital and property income, the valuable information available in Form 100 is used.

In summary, the most important variable in ES-SILC is the disposable household income. This variable is obtained as the sum of income components (salaries, pensions, etc.). In the production of these variables, information from administrative files is sometimes used. When there is no information in the questionnaires or in the administrative files, the mathematical imputation must be used.

\section{Main indicators}

Most of the studies on poverty and inequality that are obtained from EU-SILC are based on the variable "disposable household income". 
Although this variable is constructed at the household level, many indicators take the person as a unit. When transferring household information to the individuals, it must be taken into account if all household members have the same needs (per capita) or there are economies of scale (equivalence scales). In the case of the indicators of the EU-SILC, the second criterion is usually adopted.

The Spanish NSI, following the Eurostat recommendations, uses the income per unit of consumption (or equivalised disposable income) as the reference variable. This variable is defined as the ratio between the disposable household income and the number of consumption units (equivalised household size). To obtain the number of consumption units, the modified OECD equivalence scale is used:

$\begin{array}{lc}\text { First adult } & 1 \\ \text { Other people aged 14 or over } & 0.5 \\ \text { Every child under 14 years old } & 0.3\end{array}$

The unit of analysis is usually the person, so once the income per unit of consumption is calculated for each household, it is assigned to each of its members. This income per unit of consumption (or equivalised disposable income) is used in the calculation of indicators of relative poverty and income distribution.

\subsection{At-risk-of-poverty threshold}

This relative poverty threshold depends on the distribution of the income per unit of consumption, taking the person as the unit (for this reason is a relative threshold, because takes into account the situation of the population to which it belongs). The poverty threshold is recalculated each year, increasing or decreasing depending on the variation of the median of the equivalised disposable income.

This threshold is set at $60 \%$ of the median of the equivalised disposable income. Other thresholds such as $40 \%, 50 \%$ or $70 \%$ of the median can be considered. It can also be obtained by including or excluding the imputed rent in the definition of disposable household income.

\subsection{At-risk-of-poverty rate}

The at-risk-of-poverty rate is the percentage of people who are below the at-risk-of-poverty threshold.

Many of the poverty rates are broken down according to classification variables, for example age and gender shown in Table 1.

\begin{tabular}{lccc}
\hline \hline & Total & Males & Females \\
\hline \hline Total & 21.5 & 20.9 & 22.2 \\
Less than 16 years & 26.2 & 25.5 & 26.9 \\
From16 to 64 years & 22.1 & 21.3 & 23 \\
65 years or over & 15.6 & 14.7 & 16.3 \\
\hline \hline
\end{tabular}

Table 1: ES-SILC 2018. At-risk-of-poverty rate, by age and gender. (Percentages of total population in each category). Source: Own elaboration from ES-SILC 2018.

The meaning of these indicators is the percentage of people at-risk-of-poverty in each group, measuring the impact of relative poverty by groups. 


\subsection{Income inequality indicators. Gini coefficient and S80/S20 income quintile share ratio}

The Gini coefficient, shown in Table 2, is defined as the ratio between the cumulative proportion of the population ordered by equivalised income and the cumulative proportion of income received by them.

On the other hand, the S80/S20 income quintile share indicator, also shown in Table 2, is the ratio between the sum of the equivalised income of the last quintile and the first one. That is, the population are sorted by the equivalised income, taking the group of the poorest $20 \%$ and the richest $20 \%$. The sum of the equivalised income is determined for both groups, calculating the ratio between them. It will always be greater than one, having more inequality when the value is higher.

\begin{tabular}{ccc}
\hline \hline & Gini & S80/S20 \\
\hline \hline Value & 33.2 & 6.0 \\
\hline
\end{tabular}

Table 2: ES-SILC 2018. Gini coefficient and ratio S80/S20 (Values). Source: Own elaboration from ES-SILC 2018.

\subsection{AROPE indicator. People at risk of poverty or social exclusion (Europe 2020 strategy)}

The AROPE indicator (at risk of poverty or social exclusion) is an aggregate indicator that combines three concepts: at-risk-of-poverty, material deprivation and low work intensity (see Table 3). It is defined as the population that are in at least one the following situations:

- At-risk-of-poverty (60\% of the median of the equivalised income).

- In a situation of severe material deprivation. The households are lacking in at least four items from a list of nine. The nine items considered are:

- Cannot afford to go on holidays, at least one week a year.

- Cannot afford a meal of meat, chicken or fish at least every two days.

- Cannot afford to keep the home adequately warm.

- Unable to face unexpected expenses.

- Arrears in the payment of expenses related to the main dwelling (mortgage or rent, utility bills ...) or on hire purchase instalments.

- Cannot afford to have a car.

- Cannot afford to have a telephone.

- Cannot afford to have a TV.

- Cannot afford to have a washing machine.

- Households without work or with low work intensity. People living in households with very low work intensity are defined as people aged 0-59 years living in households where the adults worked $20 \%$ or less of their total potential during the previous 12 months. This variable does not apply in the case of people 60 and older.

The three concepts included in the concept of the AROPE indicator (at-risk-of-poverty, material deprivation and work intensity) do not always affect the same population, although there are intersections between them, as it is shown in Figure 4. 


\begin{tabular}{lc}
\hline \hline & Total \\
\hline \hline At risk of poverty or social exclusion & 26.1 \\
At-risk-of-poverty & 21.5 \\
Severe material deprivation & 5.4 \\
Without work or with low work intensity (from 0 to 59 years old) & 10.7 \\
\hline \hline
\end{tabular}

Table 3: ES-SILC 2018. At risk of poverty or social exclusion (AROPE) indicator and its components by gender (Percentages of total population in each category). Source: Own elaboration from ES-SILC 2018.

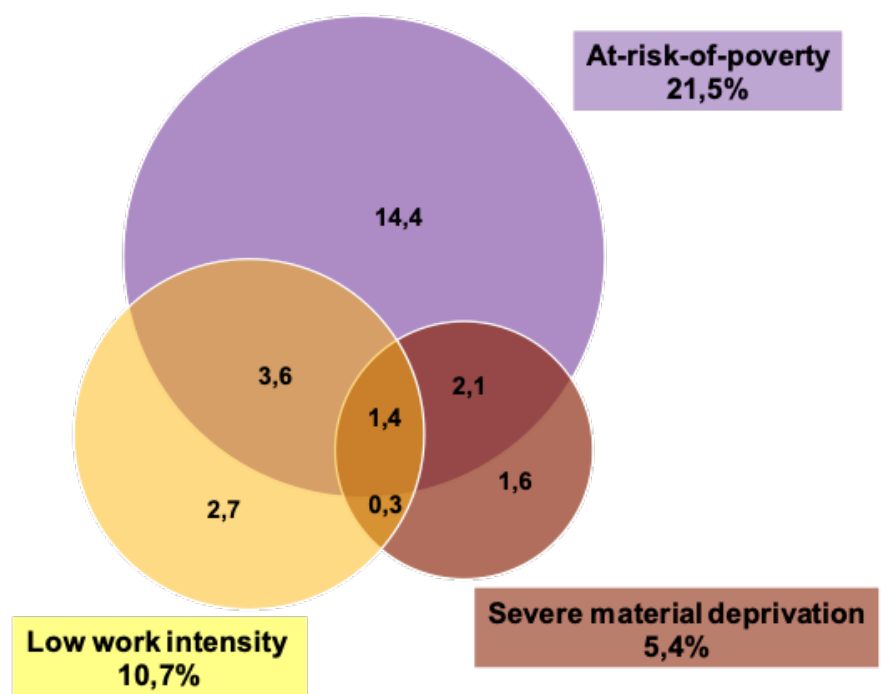

Figure 4: ES-SILC 2018. Intersections between subpopulations of AROPE Indicator. Source: Own elaboration from ES-SILC 2018.

\section{Impact of the methodological change in the ES-SILC on indicators}

In preliminary comparative studies between the ES-SILC data based on the use of the questionnaires (base 2004) and those data based on the use of administrative files (base 2013), carried out with data from the 2009 - 2012 surveys, the results presented in Table 4 were obtained.

The main conclusion of this study is that the use of administrative files has a very important impact on indicators based on the level of income, increasing significantly their value. On the other hand, there was an apparently lower impact on inequality indicators.

In the analysis of the at-risk-of-poverty indicators, it should be taken into account that the confidence intervals are quite wide (Eurostat initially published this type of indicators in whole numbers). For example, in the case of the total population, the $95 \%$ confidence interval of the at-risk-of-poverty rate in ES-SILC is around \pm 1.4 .

The comparative studies between the data obtained using questionnaires and data from administrative files are available as working papers in the Spanish NSI website (Vega et al., 2011; 2014). 


\begin{tabular}{|c|c|c|c|c|c|c|c|c|}
\hline & \multicolumn{2}{|c|}{2009} & \multicolumn{2}{|c|}{2010} & \multicolumn{2}{|c|}{2011} & \multicolumn{2}{|c|}{2012} \\
\hline & Survey & $\begin{array}{c}\text { Admin. } \\
\text { data }\end{array}$ & Survey & $\begin{array}{l}\text { Admin. } \\
\text { data }\end{array}$ & Survey & $\begin{array}{l}\text { Admin. } \\
\text { data }\end{array}$ & Survey & $\begin{array}{l}\text { Admin. } \\
\text { data }\end{array}$ \\
\hline $\begin{array}{l}\text { At risk of poverty } \\
\text { or social exclusion }\end{array}$ & 24,5 & 24,7 & 26,7 & 26,1 & 27,7 & 26,7 & 28,2 & 27,2 \\
\hline Less than 16 years & 29,8 & 31,9 & 32,1 & 32,6 & 32,3 & 31,6 & 32,8 & 31,4 \\
\hline From 16 to 64 years & 23,3 & 23,0 & 26,7 & 25,3 & 28,2 & 27,0 & 30,1 & 29,0 \\
\hline 65 years or over & 24,3 & 24,9 & 21,4 & 22,9 & 20,9 & 21,2 & 16,6 & 16,5 \\
\hline At risk of poverty & 20,1 & 20,4 & 21,4 & 20,7 & 22,2 & 20,6 & 22,2 & 20,8 \\
\hline Less than 16 years & 26,5 & 28,9 & 28,3 & 28,8 & 28,7 & 27,2 & 28,9 & 26,9 \\
\hline From 16 to 64 years & 17,9 & 17,5 & 20,1 & 18,6 & 21,3 & 19,3 & 22,4 & 20,9 \\
\hline 65 years or over & 23,1 & 23,8 & 20,5 & 21,8 & 19,5 & 19,8 & 14,8 & 14,8 \\
\hline Gini coefficient & 33,0 & 32,9 & 34,4 & 33,5 & 34,5 & 34,0 & 35,0 & 34,2 \\
\hline $\begin{array}{l}\text { S80/S20 income } \\
\text { quintile share ratio }\end{array}$ & 6,4 & 5,9 & 7,2 & 6,2 & 7,1 & 6,3 & 7,2 & 6,5 \\
\hline $\begin{array}{l}\text { Median equivalised } \\
\text { income (euros) }\end{array}$ & 14.483 & 17.042 & 14.369 & 16.922 & 13.907 & 16.280 & 13.885 & 16.119 \\
\hline
\end{tabular}

Table 4: ES-SILC. Basic indicators. Survey versus administrative files. Source: Own elaboration from ES-SILC 2018.

\section{The future of EU-SILC}

\subsection{Future plans}

One of the problems of ES-SILC is the difficulty in the territorial disaggregation of the indicators. Although some basic indicators are published at the autonomous community level (NUTS2), in general the small sample size does not allow robust estimates. In 2013 there was a request from Eurostat for the EU-SILC in order to produce high-quality regional indicators since information on poverty and inequality could be used in the allocation of cohesion funds from 2020.

The external and internal demand for better regional coverage of ES-SILC has led to a process of duplication of the sample size starting in 2019 and applied to the new sample. Being a rotating panel with four rotation groups, the final duplication will be consolidated in 2022.

A revision of EU-SILC is also planned to be implemented in 2021. The future survey will be based on a series of rotating modules that will cover different dimensions of the living conditions of the households. Each year two modules, one included every 3 years and the other every 6 years, will cover demands such as housing, child welfare, access to services, etc. The fixed core of the survey, in comparison with the current survey, will be reduced so as not to increase the total burden on the respondents (see Table 5).

This model will allow the regular inclusion of different topics related with the living conditions broadening the scope of this survey (Argüeso et al., 2013).

Regarding the mode of data collection, ES-SILC has been collected by CAPI since 2005. In 2017 a pilot test was carried out, in which the multi-channel data collection (CAWI-CATI-CAPI) has been tested. The modernization of data collection in ES-SILC will increase the efficiency of the survey, although there are also important challenges due to the specific complexity of ES-SILC and the type of information collected. 


\begin{tabular}{|c|c|c|c|}
\hline & \multicolumn{3}{|c|}{ Rolling modules } \\
\hline Nucleus (all years) & Year & 3 year rolling module & 6 year rolling module \\
\hline Income & 1 & Children & New policy needs 1 \\
\hline Material deprivation & 2 & Health & Quality of life \\
\hline Economic activity & 3 & Labour and & Intergenerational transmission \\
\hline Demography & & housing & of disadvantages and Housing \\
\hline Education & & conditions & difficulties. New policy needs 2 \\
\hline Child care & 4 & Children & Access to services \\
\hline Housing costs & 5 & Health & New policy needs 3 \\
\hline Health & 6 & Labour and & Over-indebtedness, \\
\hline Quality of life & & housing conditions & consumption and wealth \\
\hline Miscellaneous & & & \\
\hline
\end{tabular}

Table 5: Distribution of the topics among the annual survey and the rolling modules scheduled in the revision of EU-SILC. Source: Own elaboration.

\subsection{Demands from users}

The revision of ES-SILC in 2021 provides an opportunity for the inclusion of variables widely demanded by users, including additional questions in the questionnaires or collecting them from the administrative files.

The inclusion of additional questions in the questionnaires has the concern of the increase of the overload of the interview. This is particularly relevant in a future multi-channel data collection scenario, in which many interviews will be CAWI, and respondents must self-complete the questionnaire online. Nevertheless, the revised EU-SILC, with the scheme of rotating modules, will contribute to expand the content of this statistical operation addressing more in detail specifics topics like children, access to services, housing etc. widely demanded by users like the Office of the High Commissioner against Child Poverty. Also the reduction of the questionnaire due to the use of administrative files would give room for the inclusion in the future of some additional questions covering topics of national relevance like, for example, the energy poverty.

In the case of the collection of additional information from administrative sources, we have the important advantage that the respondent's burden is not increased. The demand of detailed information available in administrative databases is very important from the academic users, although it is not always possible to collect this information at microdata level for the respondents of the survey. In the case of the tax data, the main concern is the access to individual information that is restricted by the Taxation Law when this information is not included explicitly in a variable of a European regulation. Even so, there are still opportunities for the extension of the use of administrative files, in particular in variables related to the mortgage expenses of the dwelling, and in the disaggregation of some social benefits, that are included in the European regulation. Also the use of non-tax administrative databases can be envisaged.

\section{References}

Argüeso A. and Escudero T. and Méndez J.M. and Izquierdo M.J. (2013). Alternativas en la construcción de un indicador multidimensional de calidad de vida. Technical report, INE. Madrid.

European Parliament And Council Of The European Union (2003). Regulation of the European Parliament and of the Council of 16 June 2003 concerning Community Statistics on Income and Living 
Conditions (EU-SILC) (EC) No. 1177/2003. Technical report.

Eurostat (2013). The use of registers in the context of EU-SILC: challenges and opportunities. Technical report, Eurostat Statistical Working Papers. Edited by Markus Jäntti, Veli-Matti Törmälehto and Eric Marlier.

INE (2005). La Encuesta de Condiciones de Vida. Metodología. Technical report. Madrid.

United Nations (2011). Canberra Group Handbook on Household Income Statistics, 2nd edition. Technical report. New York and Geneva.

Vega P. and Méndez J.M. (2011). Linking data from administrative records and the Living Conditions Survey. Technical report, INE. Madrid.

Vega P. and Méndez J.M. (2014). Comparación de los ingresos del trabajo entre la Encuesta de Condiciones de Vida y las fuentes administrativas. Technical report, INE. Madrid. 